REVISED VERSION

\title{
Flow shear stress differentially regulates endothelial uptake of nanocarriers targeted to distinct epitopes of PECAM-1
}

\author{
Jingyan Han, ${ }^{\dagger}$, Vladimir V. Shuvaev,${ }^{\dagger}$ Peter F. Davies,,${ }^{\ddagger}$ David M. Eckmann, ${ }^{\&}$ Silvia \\ Muro," and Vladimir R. Muzykantov ${ }^{\dagger, *}$
}

tDepartment of Pharmacology and Center for Translational Targeted Therapeutics and

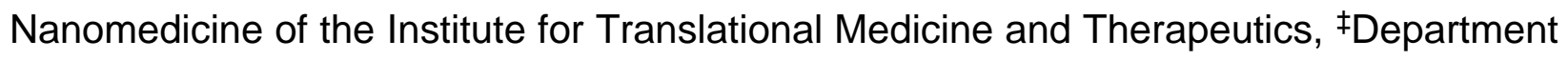
of Pathology \& Lab Medicine and Institute for Medicine and Engineering, \&Department of Anesthesiology and Critical Care, Perelman School of Medicine, University of Pennsylvania, Philadelphia, PA19104, §Vascular Biology Section, Department of Medicine, Boston University, Boston, MA 02421, and \#Fischell Department of Bioengineering, University of Maryland, College Park, MD 20742, USA

*Address correspondence to muzykantov@mail.med.upenn.edu 


\begin{abstract}
Targeting nanocarriers (NC to endothelial cell adhesion molecules including PlateletEndothelial Cell Adhesion Molecule-1 (PECAM-1 or CD31) improves drug delivery and pharmacotherapy of inflammation, oxidative stress, thrombosis and ischemia in animal models. Recent studies unveiled that hydrodynamic conditions modulate endothelial endocytosis of NC targeted to PECAM-1, but the specificity and mechanism of effects of flow remain unknown. Here we studied the effect of flow on endocytosis by human endothelial cells of $\mathrm{NC}$ targeted by monoclonal antibodies $\mathrm{Ab}_{62}$ and $\mathrm{Ab}_{37}$ to distinct epitopes on the distal extracellular domain of PECAM. Flow in the range of $1-8$

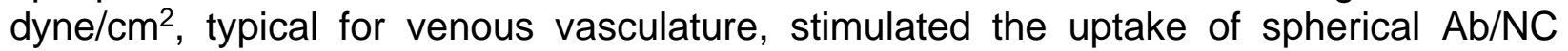
( 180 nm diameter) carrying 50 vs $200 \mathrm{Ab}_{62}$ and $\mathrm{Ab}_{37}$ per NC, respectively. Effect of flow was inhibited by disruption of cholesterol-rich plasmalemma domains and deletion of PECAM-1 cytosolic tail. Flow stimulated endocytosis of $\mathrm{Ab}_{62} / \mathrm{NC}$ and $\mathrm{Ab} 37 / \mathrm{NC}$ via eliciting distinct signaling pathways mediated by RhoA/ROCK and Src Family Kinases, respectively. Therefore, flow stimulates endothelial endocytosis of Ab/NC in a PECAM-1 epitope specific manner. Using ligands of binding to distinct epitopes on the same target molecule may enable fine-tuning of intracellular delivery based on the hemodynamic conditions in the vascular area of interest.
\end{abstract}

Key words: Intracellular delivery, endothelial cells, vascular immunotargeting, cell adhesion molecules, endocytosis, fluid shear stress 


\section{INTRODUCTION}

Cellular uptake of targeted nanocarriers (NC) for drug delivery is regulated by parameters of carrier design (e.g., selection of target epitopes), as well as target cell phenotype and factors associated with the cellular microenvironment [1-4]. Thus, experimental models for delivery of $\mathrm{NC}$ should account for target cell conditions in vivo [5-8]. For example, the functional status of endothelial cells lining the vascular lumen, an important target for drug delivery, is greatly influenced by fluid shear stress of blood flow that varies under physiological and pathological conditions [9]. The role of blood rheology and hydrodynamics in NC binding to endothelium is extensively studied [1015]. In contrast, relatively little is known about the role of these factors in the intracellular uptake of nanoparticles bound to specific endothelial surface molecules. Several lines of evidence suggest an important role of flow in the regulation of endocytosis of macromolecules and particles, such as albumin, non-targeted nanoparticles (e.g., quantum dots, $\mathrm{SiO}^{2-}$ nanoparticles [16]), and nano- and micro-sized hydrogel spheres [17].

However, the role of hemodynamics in endocytosis of NC targeted to endothelial cells by affinity ligands including antibodies (i.e., $\mathrm{Ab} / \mathrm{NC}$ ) remains enigmatic. It is plausible that flow regulates this process in a ligand-specific fashion, since nature of the binding site and mode of ligand engagement control the mechanism of endocytosis. Recent studies in vitro and in vivo revealed that flow conditions modulate endothelial endocytosis of $\mathrm{Ab} / \mathrm{NC}$ targeted to the cell adhesion molecules ICAM-1 and PECAM-1 $[12,18]$. Drug delivery using $\mathrm{Ab} / \mathrm{NC}$ targeted to these determinants improves therapeutic effects of experimental drugs and biotherapeutics in animal models [19-22]. This justifies efforts directed towards extending our knowledge of the factors controlling intracellular delivery of NC targeted to these molecules. PECAM-1 antibodies bind to endothelial cells but do not accumulate significantly in the intracellular compartments $[23,24]$. In contrast, the multivalent binding of NCs coated with PECAM-1 antibody (e.g., $\mathrm{Ab} / \mathrm{NC}$ ) leads to intracellular uptake mediated by the pathway known as CAMendocytosis, distinct from clathrin- or caveolae-mediated endocytosis, phagocytosis and macropinocytosis [23,25]. Furthermore, recent studies showed that shear stress stimulates endocytosis of PECAM-1-targeted Ab/NC [18].

However, previous studies revealed that under standard static cell culture conditions, human endothelial cells differentially internalize $A b / N C$ targeted to specific PECAM-1 epitopes: e.g., they internalize Ab/NC targeted by monoclonal antibody 62 $\left(A_{62}\right)$ but not by monoclonal antibody $37\left(A_{37}\right)$, which both are directed to distinct epitopes located in the distal Ig-like domain of PECAM-1 (i.e., A $b_{62} / \mathrm{NC}$ and $\mathrm{A} b_{37} / \mathrm{NC}$, respectively) [26]. These findings imply that control of endothelial internalization by physiological factors including flow may be different for Ab/NC targeted to distinct epitopes of PECAM-1. In the present study we have investigated whether this effect of flow is epitope-specific. 


\section{RESULTS}

Flow differently modulates endothelial internalization of $A b / N C$ targeted to distinct PECAM-1 epitopes. Binding to and uptake by target cells are proportional to $\mathrm{Ab} / \mathrm{NC}$ 's avidity, controlled by antibody affinity and number on a NC surface. Coupling $\sim 200$ antibody molecules per $100 \mathrm{~nm}$ particle provides nearly maximal surface density of monolayer IgG coating [27]. We started with assessing the uptake by endothelial cells of such NC coated by $A b_{37}$ vs $A b_{62}$, either at static conditions or 30 minutes after exposure to non-pulsatile laminar flow generating a flow shear stress of $4 \mathrm{dyne} / \mathrm{cm}^{2}$. Double-label fluorescent microscopy with secondary fluorescent antibody allows to distinguish cell surface-bound vs intracellular fluorescent nanocarriers (Fig.1A). We found that flow almost doubles uptake of $\mathrm{Ab}_{37} / \mathrm{NC}$, which are barely internalized by static endothelial cells (Fig. 1A \& B). However, flow rather trivially augmented uptake of $\mathrm{Ab}_{62} / \mathrm{NC}$, which are effectively internalized by static cells (Fig. 1A \& B).

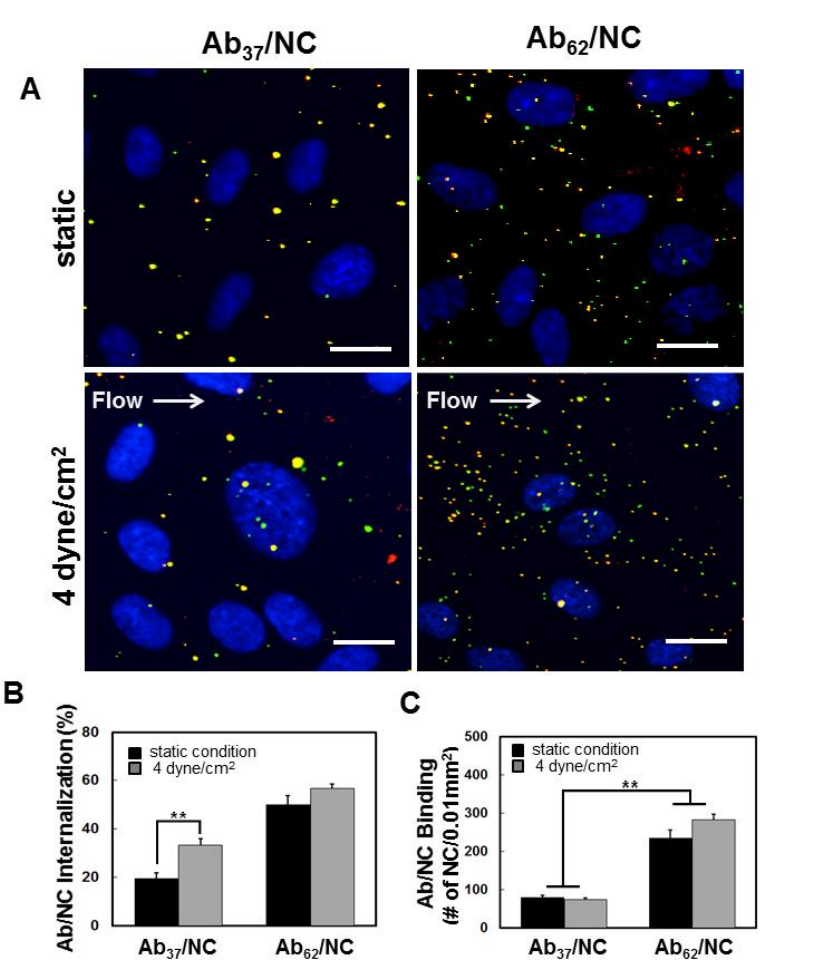

Figure 1. Endothelial binding and internalization of nanocarriers coated by $A b_{37}$ and $A b_{62} . A$, Representative fluorescence images showing endothelial binding (total particles) and internalization (green particles) of $\mathrm{NC}$ coated with $A b_{37}$ (left panel) versus $A b_{62}$ (right panel) at maximal $\mathrm{Ab}$ density on the surface of NC (200Abs/NC) under static and laminar flow conditions. Scale bar is $20 \mu \mathrm{m}$. B and $C$, confluent endothelial cells were incubated or exposed to flow (4 dyne $\left./ \mathrm{cm}^{2}\right)$ with $\mathrm{Ab} / \mathrm{NC}$ at the NC concentration of $2 \times 10^{9} / \mathrm{ml}$ for $30 \mathrm{~min}$ at $37^{\circ} \mathrm{C}$. Flow stimulates internalization of $A b_{37} / \mathrm{NC}(B)$. Fewer $A b_{37} / \mathrm{NC}$ were bound to endothelial cells under static and flow conditions (C). The percentage of $\mathrm{Ab} / \mathrm{NC}$ internalized into endothelial cells $(B)$ and total number of $A b / N C$ bound to endothelial cells $(C)$ in each image field $\left(0.01 \mathrm{~mm}^{2}\right)$ were quantified by fluorescence microscopy and presented as Mean \pm S.E. $(n=$ 8). ${ }^{\star} p<0.05,{ }^{* *} p<0.01$.

The binding of $A b_{37} / \mathrm{NC}$ to endothelial cells was markedly lower than that of $\mathrm{Ab}_{62} / \mathrm{NC}$ (Supplemental table 2 and Fig.1A and C). Noteworthy, flow stimulated internalization of $A b_{37} / \mathrm{NC}$ without changing its binding (Fig.1B and $\mathbf{C}$ ). The data of uptake of $\mathrm{Ab} / \mathrm{NC}$ incubated at different concentrations with static cells further distinguished binding vs internalization. As expected, endothelial binding of both types of $\mathrm{Ab} / \mathrm{NC}$ increased proportionally to their concentration (Fig.2A). Importantly, binding of $\mathrm{Ab}_{37} / \mathrm{NC}$ at high concentration exceeded that of $\mathrm{Ab}_{62} / \mathrm{NC}$ at low concentration. However, the level of $A b_{37} / \mathrm{NC}$ internalization remained consistently three-fold lower than that of Ab ${ }_{62} / \mathrm{NC}$, i.e., $~ 20 \%$ vs $60 \%$ (Fig.2B). Taken together, these data indicate that both $\mathrm{Ab} / \mathrm{NC}$ internalization and its modulation by flow do not necessarily correlate directly 
with number of cell-bound $\mathrm{Ab} / \mathrm{NC}$. This is important in the context of the effects of flow

A

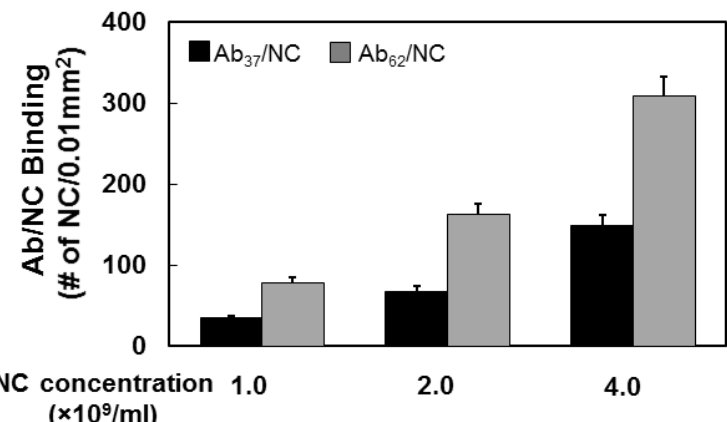

$\left(\times 10^{9} / \mathrm{ml}\right)$

B

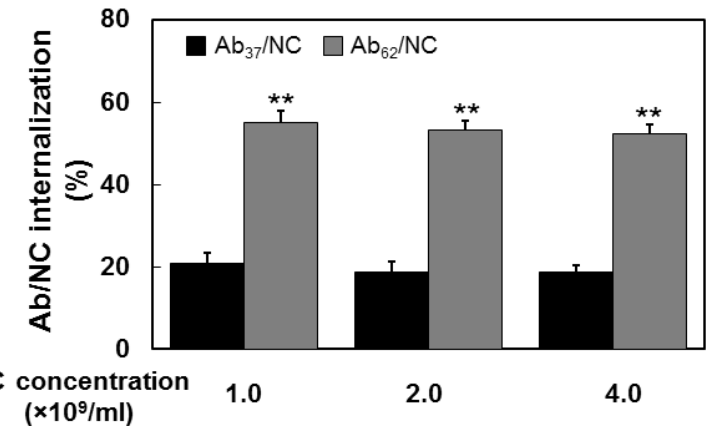

in endocytosis of $\mathrm{Ab} / \mathrm{NC}$ (see Discussion).

Figure 2. Endocytosis of $A b_{37} / \mathrm{NC}$ and $A b_{62} / \mathrm{NC}$ is independent of the total number of $\mathrm{Ab} / \mathrm{NC}$ bound to endothelial cells. $A, A b_{37} / \mathrm{NC}$ and $\mathrm{Ab}_{62} \mathrm{NC}(200 \mathrm{Ab} / \mathrm{NC})$ at different concentration (1, 2 , and $4 \times 10^{9}$ particles $/ \mathrm{ml}$ ) were incubated with confluent endothelial cells for 30 minutes. The total number of $A b_{37} / \mathrm{NC}$ (black bar) and $A b_{62} / \mathrm{NC}$ (gray bar) bound to cells and their internalization (insert) in each image field $\left(0.01 \mathrm{~mm}^{2}\right)$ were quantified by fluorescence microscopy.

However, antibody surface density, which controls valence and avidity of binding, is an important factor in flow-mediated stimulation of the $\mathrm{Ab} / \mathrm{NC}$ uptake. First, reduction of surface density of $\mathrm{Ab} 62 / \mathrm{NC}$ coating from $\sim 200$ to 50 antibody molecules per particle decreased endothelial endocytosis to the level comparable with that of $A b_{37} / \mathrm{NC}$ carrying 200 antibody molecules

(Fig.3A). Second, flow stimulated endocytosis of $\mathrm{Ab}_{62} / \mathrm{NC}$ with low Ab density similarly to that of $A b_{37} / \mathrm{NC}$ with high $\mathrm{Ab}$ density. Finally, flow ranging from 1 to $8 \mathrm{dyne} / \mathrm{cm}^{2}$ showed a trend to stimulate proportionally endocytosis of $A b_{37} / \mathrm{NC}$ carrying $\sim 50 \mathrm{Ab}$ molecules, but this trend did not reach statistical significance (Fig.3B).

A

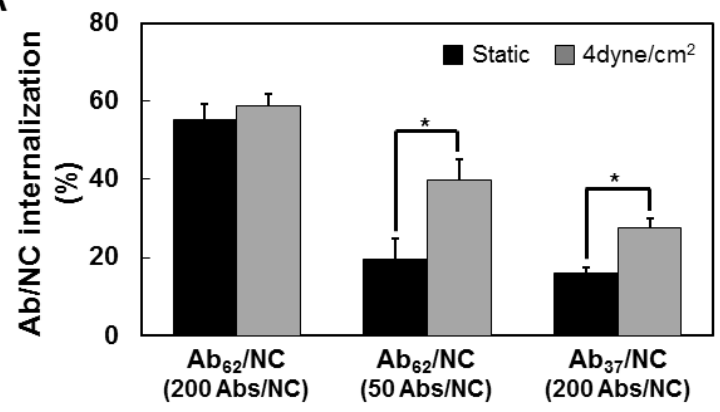

B

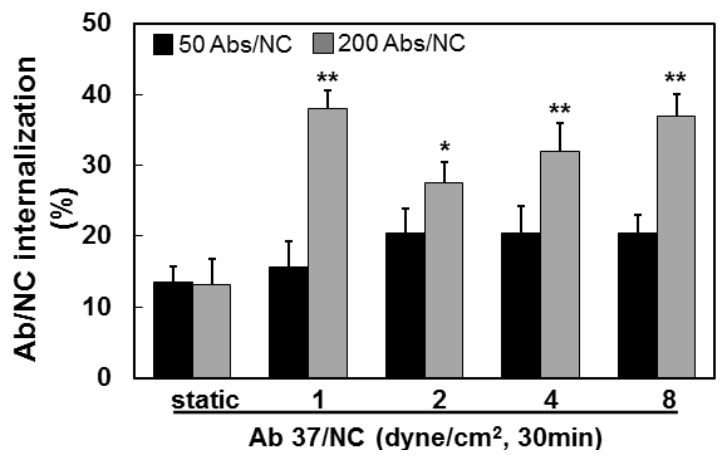

Figure 3. Fluid shear stress stimulates endocytosis of $A b_{37} / \mathrm{NC}$ and $A b_{62} / \mathrm{NC}$ : role of $\mathrm{Ab} / \mathrm{NC}$ avidity. $A$, internalization of $\mathrm{Ab}_{62} / \mathrm{NC}(50$ and $200 \mathrm{Abs} / \mathrm{NC}$ ) and $\mathrm{Ab}_{37} / \mathrm{NC}(200 \mathrm{Abs} / \mathrm{NC})$ under static and flow conditions (incubation or perfusion at 4 dyne $/ \mathrm{cm}^{2}$ for 30 minutes) were quantified. $B$, internalization of $A b_{37} / \mathrm{NC}$ at low (50 $\mathrm{Abs} / \mathrm{NC}$ ) and high (200 Abs/NC) antibody density over particle surface in endothelial cells was quantified under static or flow $(1,2,4,8$ dyne $/ \mathrm{cm}^{2}, 30$ minutes) conditions ${ }^{*} p<0.05,{ }^{* *} p<$ 0.01 in comparison with static groups.

These data show that flow stimulates endocytosis of $\mathrm{Ab} / \mathrm{NC}$ within a restricted range of $\mathrm{Ab} / \mathrm{NC}$ avidity to endothelium. For $A b_{62} / \mathrm{NC}$ and $A b_{37} / \mathrm{NC}$, it is close to that provided by low and high antibody density, respectively. Exceeding this empirical range, 
e.g., by using high antibody density $A b_{62} / \mathrm{NC}$ results in a high internalization rate overshadowing the effect of flow, whereas falling below this range (e.g., by using low $A b$ density $A b_{37} / \mathrm{NC}$ ) inhibits the internalization beyond that which is salvageable by stimulatory flow effect.

Cholesterol-rich plasmalemma domain(s) and PECAM-1 cytosolic tail mediate stimulation of endocytosis of $A b_{62} / \mathrm{NC}$ and $A b_{37} / \mathrm{NC}$ by flow. Next, we addressed cellular mechanisms involved in stimulation of endocytosis by flow. Here we focused on two factors: sensing of flow by cholesterol-rich domains in the plasmalemma and signaling via PECAM-1 anchoring molecule.

First, we found that cholesterol sequestration by methyl- $\beta$-cyclodextrin, which affects the lipid rafts and caveolae, abrogated stimulatory effect of flow on endothelial endocytosis of $A b_{37} / \mathrm{NC}$ and $\mathrm{Ab}_{62} / \mathrm{NC}$ (high and low antibody density formulations, respectively), without affecting their internalization under static conditions (Fig.4).

A

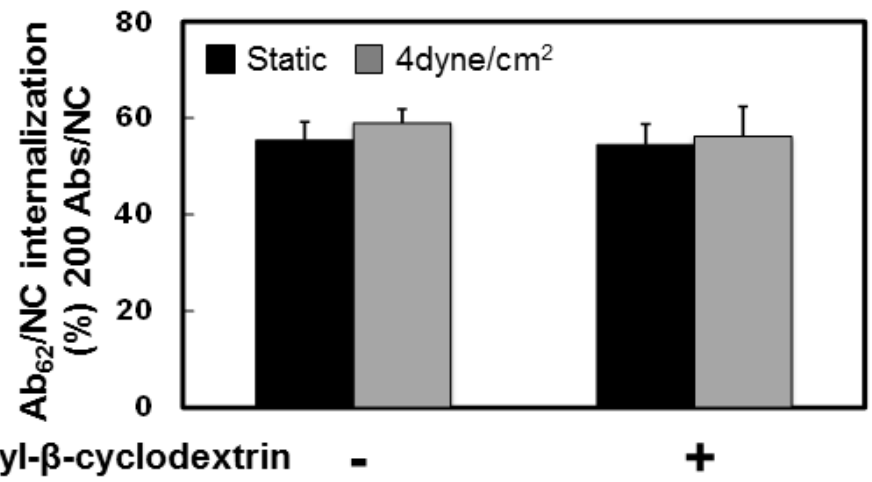

B

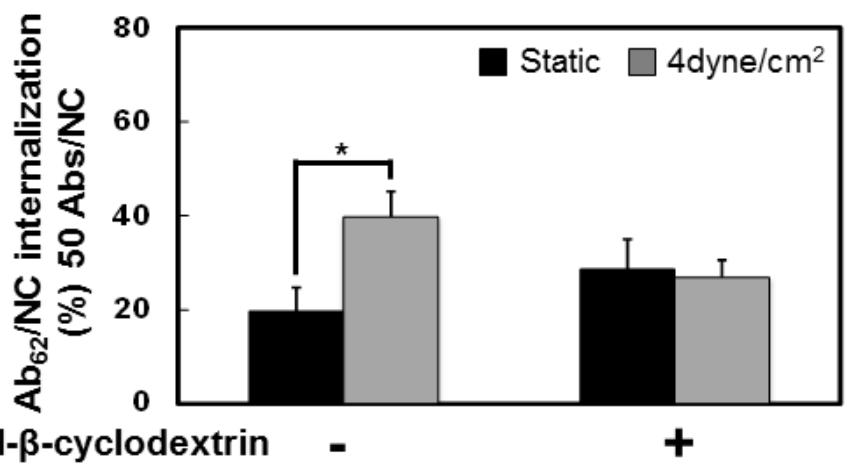

Methyl- $\beta$-cyclodextrin

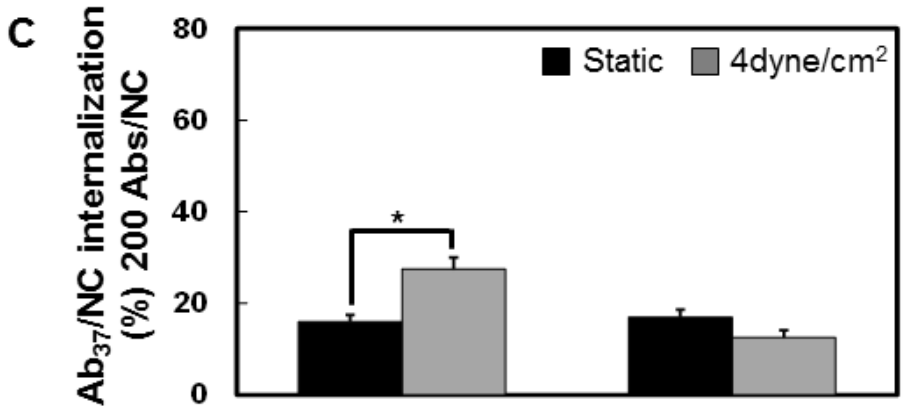

Methyl- $\beta$-cyclodextrin
Figure 4. Disruption of lipid rafts abolished the shear stressstimulated endocytosis of $A b_{37} / \mathrm{NC}$ and $A b_{62} / \mathrm{NC}$. Methyl- $\beta$ cyclodextrin pretreatment inhibited shear stress (4 dyne $\left./ \mathrm{cm}^{2}\right)$-induced endocytosis of $A b_{62} / \mathrm{NC} \quad(200$ $\mathrm{Abs} / \mathrm{NC}, A),(50 \mathrm{Abs} / \mathrm{NC}, B)$ and $\mathrm{Ab}_{37} / \mathrm{NC}$ (200 Abs/NC, C). Confluent endothelial cells were pre-treated with Methyl- $\beta$-cyclodextrin $(1 \mathrm{mM})$ for 30 minutes, followed by incubation or perfusion of $\mathrm{Ab} / \mathrm{NC}$ for 30 minutes in the presence of Methyl- $\beta$ cyclodextrin. Internalization of $\mathrm{Ab} / \mathrm{NC}$ was analyzed and expressed as Mean \pm S.E. $\left(\mathrm{n}=6,{ }^{*} p<0.05\right.$, in comparison with static groups).

Second, we tested whether signaling via PECAM-1 intracellular domain is involved in flow-stimulated endocytosis of $\mathrm{Ab} / \mathrm{NC}$. We employed REN cells (which are naturally PECAM-1 null) transfected with full-length PECAM-1 vs mutant PECAM-1 lacking the cytosolic domain, as described in our previous work [18]. The results shown in Fig.5A indicate that: i) flow does stimulate uptake of $A b_{37} / \mathrm{NC}$ by non-endothelial REN cells expressing full-length PECAM-1, which is similar to our observation in endothelial cells and thus validates this model; and, ii) deletion of 
PECAM-1 cytosolic domain abrogates this effect of flow. Further, flow did not enhance endocytosis of either $A b_{62} / \mathrm{NC}$ or $\mathrm{Ab}_{37} / \mathrm{NC}$ (50 and $200 \mathrm{Ab}$ per NC, respectively) in REN cells expressing phosphorylation deficiency mutant (Y686F) of PECAM-1 (Fig.5B).

A

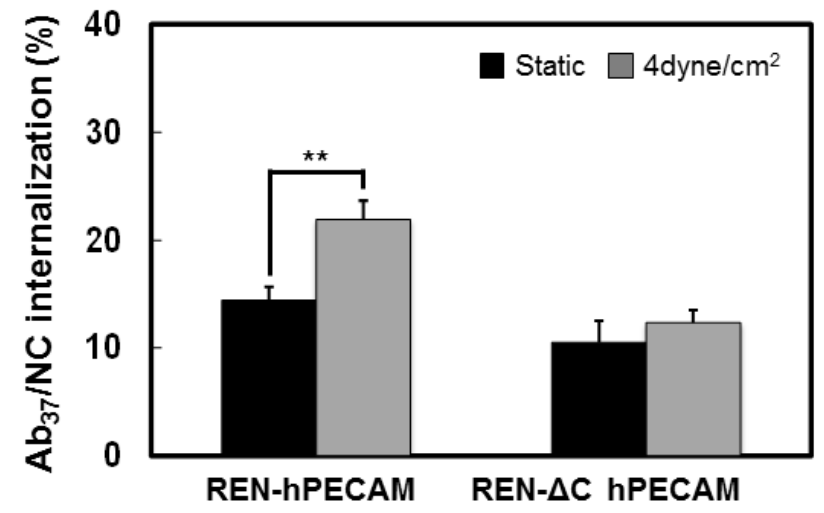

B

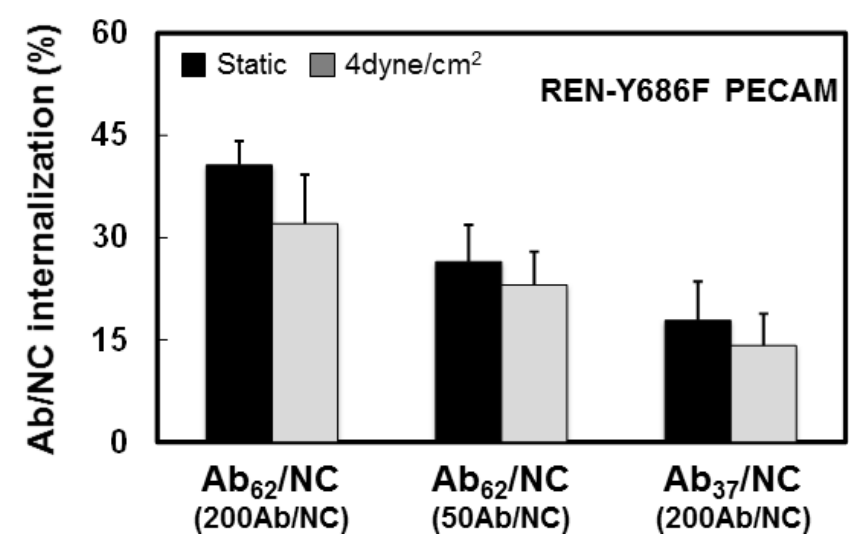

Therefore, flow stimulates Ab/NC endocytosis via signaling pathway(s) involving cholesterol-rich domains of plasmalemma and Tyr686 in cytosolic tail of PECAM-1.

Figure 5. Phosphorylation of PECAM1 cytoplasmic domain is required for fluid shear stress-stimulated endocytosis of Ab/NC. A, Cytoplasmic domain of PECAM-1 mediated the stimulatory effect of flow $\left(4 \mathrm{dyn} / \mathrm{cm}^{2}, 30\right.$ minutes) on endocytosis of $A b_{37} / \mathrm{NC}$. $B$, Expression of phospho-defective PECAM-1 mutant Y686F inhibited flowstimulated endocytosis of $\mathrm{Ab}_{37} / \mathrm{NC}(200$ $\mathrm{Ab} / \mathrm{NC})$ and $A b_{62} / \mathrm{NC}(50 \mathrm{Ab} / \mathrm{NC})$. REN cells stably expressing human PECAM$1 \mathrm{WT}$ and cytoplasmic domain deleted mutant $\triangle \mathrm{CD}(A)$, or phosphor-defective mutant Y686F $(B)$ were incubated or perfused with $A b_{37} / \mathrm{NC}$ for 30 minutes at $37{ }^{\circ} \mathrm{C}$. Internalization of $\mathrm{Ab}_{37} / \mathrm{NC}$ and $\mathrm{Ab}_{62} / \mathrm{NC}$ was analyzed and expressed as Mean \pm S.E. $\left(\mathrm{n}=6,{ }^{* \star} p<0.01\right)$

Stimulation of endothelial uptake of $A b_{62} / \mathrm{NC}$ and $\mathrm{Ab}_{37} / \mathrm{NC}$ by flow involves different intracellular signaling pathways. We addressed the role of RhoA/ROCK signaling pathway(s) and actin cytoskeleton rearrangements in modulation of $\mathrm{Ab} / \mathrm{NC}$ internalization by flow. Treatment of endothelial cells with Y-27632, a pharmacological agent that inhibits RhoA/ROCK, decreased polymerized actin bundles in endothelial cells under static conditions, and prevented rearrangement of the endothelial actin cytoskeleton in response to flow (Fig.6A), in accord with the literature establishing the pivotal role of RhoA/ROCK signaling in dynamic regulation of cytoskeleton in endothelial cells. Based on this, we examined the role of this signaling in regulation of endocytosis of $\mathrm{Ab} / \mathrm{NC}$ by flow. We found that inhibition of RhoA/ROCK by Y-27632: i) suppressed internalization of high-avidity $\mathrm{Ab}_{62} / \mathrm{NC}$ (200 Abs/NC) under both static and flow conditions (Fig.6B); ii) abrogated flow-induced stimulation of uptake of low avidity Ab62/NC (50 Abs/NC, Fig.6C); and, iii) in stark contrast, did not affect the stimulatory effect of flow on $\mathrm{Ab}_{37} / \mathrm{NC}$ uptake (Fig.6D). This result suggests that flow stimulates endocytosis of $A b_{62} / \mathrm{NC}$ and $A b_{37} / \mathrm{NC}$ via different signaling mechanisms. 


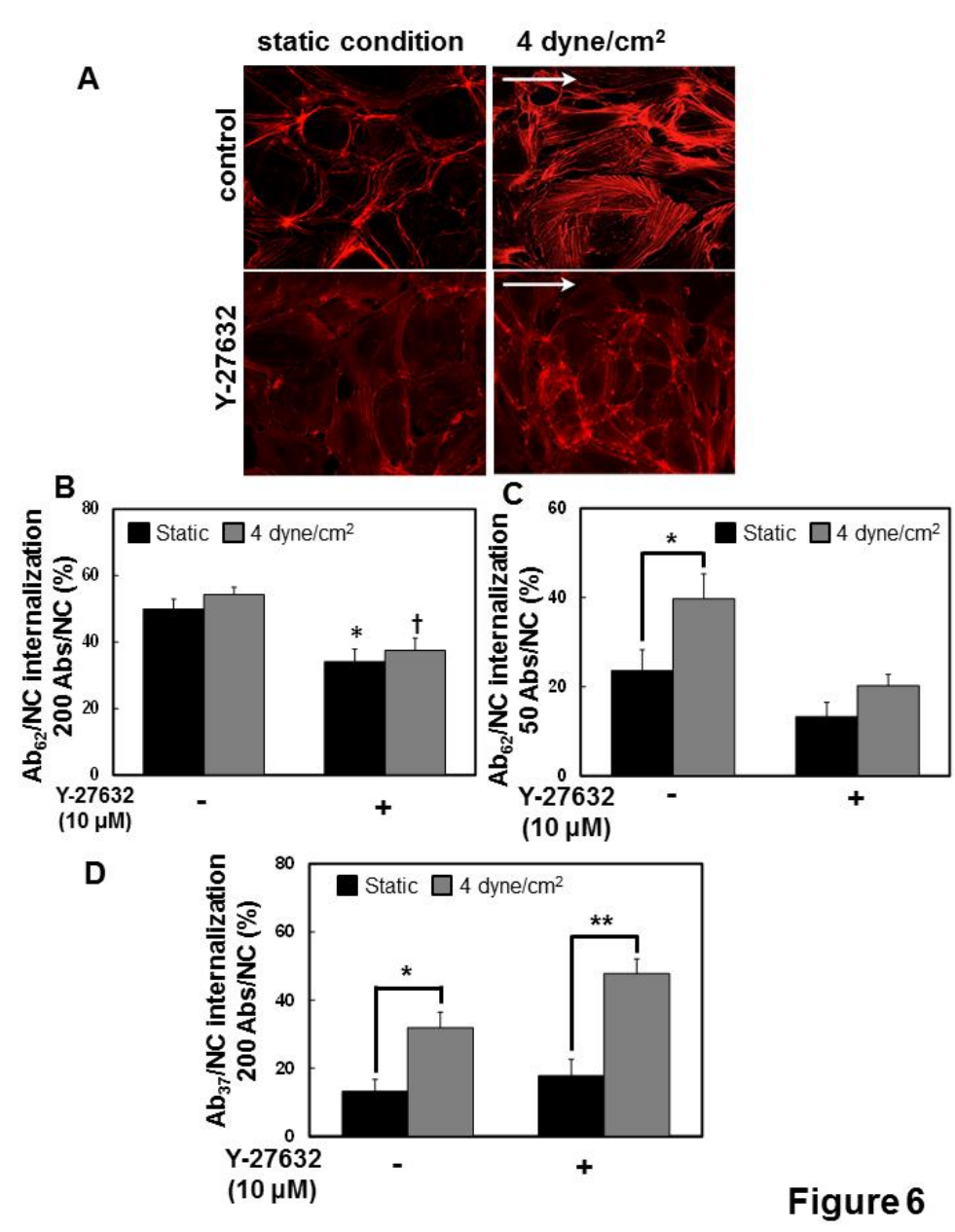

Figure 6. Blockage of RhoA/ROCK signaling pathway specifically inhibits shear stressinduced endocytosis of $A_{6} / \mathrm{NC}$. A, Y-27632, a Rho-kinase inhibitor, prevented cytoskeletal remodeling in response to flow dependent shear stress. Confluent endothelial cells were incubated or perfused at a flow of 4 dyne $/ \mathrm{cm}^{2}$ with culture medium in the absence or presence of Y-27632 $(10 \mu \mathrm{M})$ for 30 minutes. Cells were then fixed and stained for F-actin using Alexa-Fluor594phalloidin. Images were taken using fluorescence microscope with a Plan Apo 40x oil objective. Arrows show direction of flow. $B$ and $C$, pretreatment of endothelial cells with Y-27632 (10 $\mu \mathrm{M}, 30$ minutes) diminished the endocytosis of $\mathrm{Ab}_{62} / \mathrm{NC} \quad(200 \mathrm{Abs} / \mathrm{NC} \quad(A), \quad 50$ Abs/NC (B)) under both static and flow conditions. $D, \quad \mathrm{Y}-27632$ pretreatment did not inhibit shear stress-stimulated endocytosis of $\mathrm{Ab}_{37} / \mathrm{NC}(200 \mathrm{Abs} / \mathrm{NC})$. * ${ }^{*} p<0.05$, ${ }^{* *} p<0.01$ in comparison with static Figure 6 groups.

Finally, we tested the role of Src-family kinases (SFK). In a sharp contrast to RhoA/ROCK inhibition, pharmacological inhibition of SFKs by pretreatment of endothelial cells with PP2 had no effect on flow-induced stimulation of the uptake of $A b_{62} / \mathrm{NC}$, whereas it abrogated flow-induced stimulation of $A b_{37} / \mathrm{NC}$ internalization (Fig.7). 

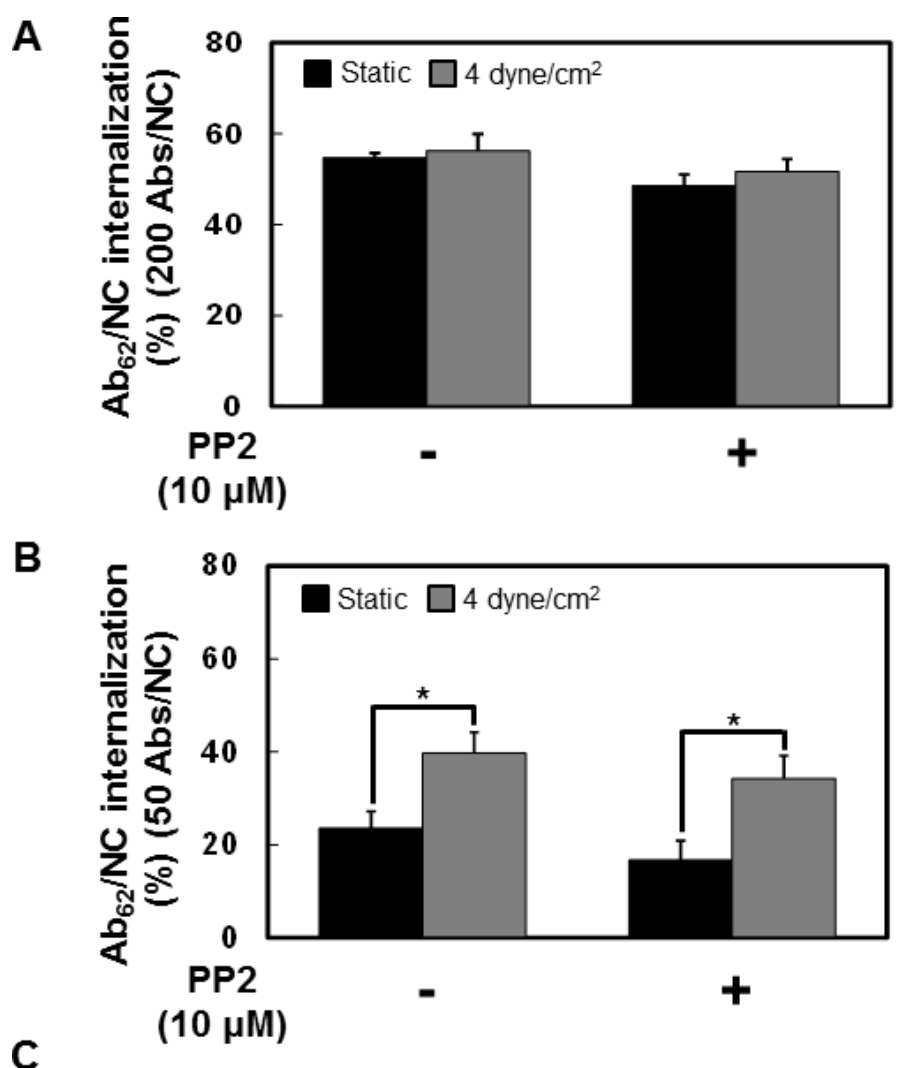

C

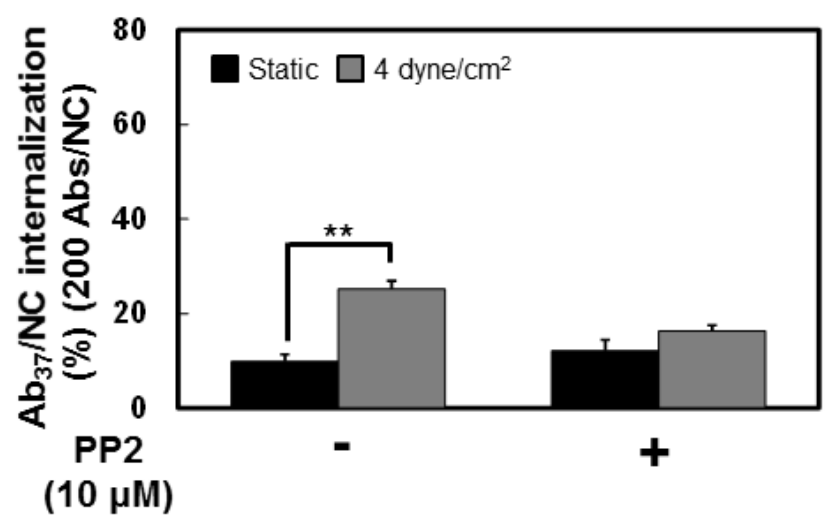

Figure 7. Inhibition of Src family kinases specifically abolishes fluid shear stress-induced endocytosis of $\mathrm{Ab}_{37} / \mathrm{NC}$. $A$ and $B$, pretreatment of endothelial cells with PP2 (10 $\mu \mathrm{M})$, Src family kinases inhibitor, could not inhibit the endocytosis of $A b_{62} / \mathrm{NC}$ $(200 \mathrm{Abs} / \mathrm{NC}(A), 50 \mathrm{Abs} / \mathrm{NC}(B))$ under either static or flow conditions. $C$, PP2 pretreatment inhibited shear stress-stimulated endocytosis of $\mathrm{Ab}_{37} / \mathrm{NC}(200 \mathrm{Abs} / \mathrm{NC}) .{ }^{*} p<0.05,{ }^{* *} p$ $<0.01$ in comparison with static groups. 


\section{DISCUSSION}

PECAM-1, a cell adhesion molecule abundantly expressed in endothelial cells, supports adhesion and trans-endothelial migration of leukocytes in inflammation sites [28-30]. Among other endothelial surface determinants, PECAM-1 is emerging as an attractive target for endothelial drug delivery [23,31,32]. Drug-loaded NC targeted to PECAM-1 bind to the endothelium and exert therapeutic effects unattainable by nontargeted drugs in animal models [32-35]. Further, endocytosis induced by multivalent $\mathrm{Ab} / \mathrm{NC}$ targeted to PECAM-1 enables intra-endothelial delivery of carriers and their cargos $[21,22,36]$. Understanding the factors controlling endothelial delivery of $\mathrm{Ab} / \mathrm{NC}$ may help to optimize drug delivery and precise addressing at the sub-cellular level, further improving therapeutic potential of this prospective drug delivery system.

Previous studies revealed that endocytosis of $\mathrm{Ab} / \mathrm{NC}$ is modulated by: i) microenvironment and physiological state of endothelium; ii) specificity of binding to distinct epitopes on PECAM-1; and, iii) Ab/NC configuration (e.g., antibody surface density). Present study extends these paradigms in the context of flow, an important factor of vascular physiology that influences all aspects of $\mathrm{Ab} / \mathrm{NC}$ targeting including its delivery to, binding and internalization by endothelium.

In this context, it is important to consider targeting features of the PECAM-1 antibodies employed in the study and distinguish $\mathrm{Ab} / \mathrm{NC}$ internalization from binding. The data of previous studies, summarized in Supplemental table 1, indicate that $A b_{62}$ and $A b_{37}$ bind to distinct epitopes in the most distal Ig-like domain 1 (IgD1) of the extracellular portion of human PECAM-1 [37]. Noteworthy, despite the fact that $A b_{37}$ has a higher endothelial affinity than $A b_{62}$ [38], A $b_{62} / \mathrm{NC}$ bind to endothelial cells better than $\mathrm{Ab}_{37} / \mathrm{NC}$ (Fig.1A). This outcome implies that either: i) avidity of $\mathrm{Ab} 62 / \mathrm{NC}$ is higher (e.g., due to less damaging immobilization or more optimal antibody orientation on the particle surface); or/and, ii) the accessibility of Ab62 epitope for multivalent binding of large ligands is superior to that of $A b_{37}$.

The defining specific aspects of binding and internalization is important, since $\mathrm{Ab} / \mathrm{NCs}$ induce endocytosis by PECAM-1 cross-linking caused by multivalent binding. In theory, binding of more Ab/NC engaging more copies of PECAM-1 molecules per cell (attained by $A b_{62} / \mathrm{NC}$ vs $\mathrm{Ab}_{37} / \mathrm{NC}$ ) may elicit stronger endocytic signal. However, data shown in Fig.2 indicate that endocytosis of $\mathrm{Ab} / \mathrm{NC}$ is modulated by strength of signaling from an individual $A b / N C$ anchored to PECAM-1, not the total number of cell-bound $\mathrm{Ab} / \mathrm{NC}$ particles or the total number of PECAM-1 copies engaged. This squares well with previous observations for NC targeted to the CAM pathway $[12,18,26]$.

Blood flow alters the adhesive interactions between $\mathrm{Ab} / \mathrm{NC}$ and endothelium $[27,39]$. Flow-driven rolling on the endothelial surface may assist $\mathrm{Ab} / \mathrm{NC}$ in engaging PECAM-1, thereby increasing the strength of CAM-endocytic signaling. Alternatively, rotational motion due to the flow-derived torque force applied to PECAM-1-anchored $\mathrm{Ab} / \mathrm{NCs}$ may further mechanically stimulate endothelial cells and enhance signaling for $\mathrm{Ab} / \mathrm{NC}$ internalization.

On the other hand, flow is known to modulate many parameters of the endothelial functional status, some of which may be involved in endocytic processes directly or indirectly. In fact, shear stress governs endothelial processes including cytoskeletal remodeling, gene expression, ion transport and endocytosis [40]. It has 
long been recognized that internalization of extracellular fluid and macromolecules such as LDL into endothelial cells is stimulated by flow [40,41]. Stimulatory effects of flow has been observed in endothelial pinocytosis [40,42], clathrin-dependent $[41,42]$, and CAMdependent endocytosis $[12,18]$. It is conceivable that flow stimulates endocytosis via a generalized mechanism, such as enhancement of the rate of plasmalemma vesicle maturation, or dynamic changes of the cytoskeleton.

However, one could also expect that at least some components of mechanisms of flow-sensitive modulation of endocytosis are specific for distinct types of endocytic processes and, perhaps, distinct receptors and ligands. For example, flow stimulates uptake of albumin in kidney proximal tubule cells via a clathrin-dependent endocytic pathway [42]. Findings presented in our study showed for the first time that distinct mechanisms mediate flow-stimulated endothelial endocytosis of Ab/NC targeted to different epitopes of PECAM-1.

Studies in static endothelial cells showed that PECAM-1 multivalent engagement by $\mathrm{Ab} / \mathrm{NCs}$ activates signaling mediated by small GTPase RhoA/ROCK pathway, leading to rapid formation of actin stress fibers, necessary for CAM-endocytosis [25,26]. In addition to "facultative" involvement in CAM-endocytosis serving "quasi-physiological" internalization of artificial objects such as $A b / N C, R h o A / R O C K$ is the key regulator of physiological dynamic actin rearrangements underlying endothelial responses to mechanical forces [43]. Therefore, rearrangements of actin cytoskeleton play a complex role both in Ab/NC uptake [12,18,44] and in cellular responses to shear stress [45]. On one hand, CAM-endocytosis requires recruitment of actin to the sites of Ab/NC binding and formation of stress fibers involved in vesicular uptake $[46,47]$, on the other hand, RhoA-mediated signaling to cytoskeleton is required for endothelial functional responses to flow in the signaling chain components downstream of PECAM-1 [48]. Chronic flow exposure causes substantial commitment of actin to stable flow directionoriented stress fibers thereby limiting actin recruitment to the endocytic pool and inhibiting CAM-endocytosis $[12,18]$. In contrast, transient exposure to flow stimulates CAM-endocytosis, perhaps by priming actin-rearrangement. The latter mechanism may be involved in the phenomena observed in the present study as well.

The complexity of mechanisms underlying $\mathrm{Ab} / \mathrm{NC}$ endocytosis and its regulation by flow is emphasized by the fact that PECAM-1 also functions as an endothelial sensor for biomechanical stimuli including hemodynamic factors [49-51]. Thus, phosphorylation at Tyr686 residue in PECAM-1 cytosolic domain is the key event in both endothelial flow shear stress sensing $[49,52]$ and Ab/NC internalization caused by engagement of the extracellular region under static condition $[26,53]$.

Furthermore, in addition to RhoA/ROCK pathway, the Src family kinases (SFKs) signaling pathway is involved in both endothelial flow sensing and Ab/NC endocytosis. SFKs are signaling enzymes regulating cellular proliferation, survival, migration and metastasis [54,55]. In particular, flow causes SFK-dependent signaling in endothelial cells via PECAM-1 phosphorylation at Tyr686 [56-59]. Activation of SFKs is also involved in endocytic pathways, including caveolae- and CAM-mediated endocytosis [25,60,61]. Results shown in Fig. 6 and 7 indicate that stimulation of internalization of $\mathrm{Ab}_{62} / \mathrm{NC}$ and $\mathrm{Ab}{ }_{37} / \mathrm{NC}$ involve alternatively RhoA/ROCK and SFK signaling pathways, respectively. 
In addition to PECAM-1, specific microdomains of plasma membrane enriched in cholesterol and sphingolipids, i.e., lipid rafts and caveolae, function in endothelial cells as sensing and signaling platforms for mechanotransduction [62]. These microdomains are also involved in membrane trafficking and vesicular uptake and transport [63]. Signaling and endocytic pathways sensitive to cholesterol depletion include lipid rafts, caveolae and several forms of pinocytosis [62-67]. Numerous studies showed that $\mathrm{Ab} 62 / \mathrm{NCs}$ do not co-localize in caveolar markers during endocytosis under either static [25] or flow conditions [18]. Flow also has been shown to stimulate endothelial pinocytosis [40]. However, Ab/NC endocytosis via PECAM-1 is clearly distinct from this receptor-independent constitutive pathway for fluid-phase uptake [68]. Therefore, it is more plausible that cholesterol-rich membrane domains play indirect signaling rather than direct endocytic function in stimulation of $\mathrm{Ab} / \mathrm{NC}$ internalization. Perhaps, auxiliary signaling via these domains in response to flow augments mechanosensing and endocytic functions mediated by PECAM-1. These signaling pathways are not yet fully understood but include the interplay between blood flow, cholesterol-rich plasmalemma domains, cytoskeleton rearrangements, Tyr686 phosphorylation of PECAM-1 and signaling via RhoA/ROCK and SFK (see a hypothetic schema in Fig.8).

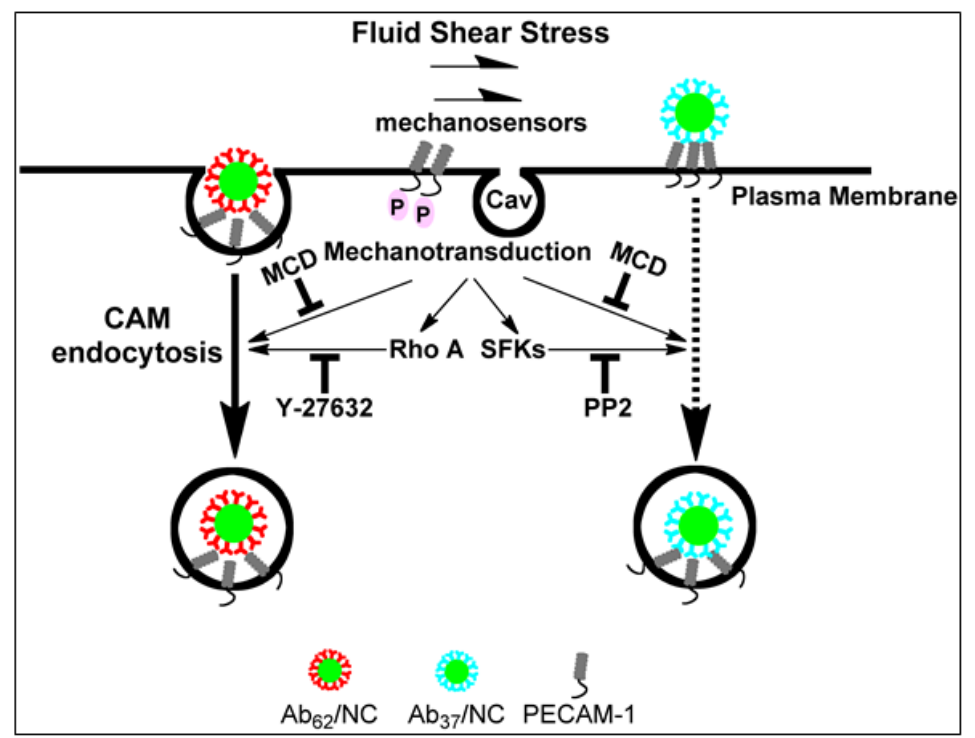

Figure 8. Fluid shear stress stimulates the endocytosis of $A b_{37} / N C$ and $A b_{62} / N C$ via distinct mechanisms. Disruption of lipid rafts by methyl- $\beta$-cyclodextrin, a cholesterol chelator, abolishes acute shear stress-induced endocytosis of $A b_{62} / \mathrm{NC}$ and $A b_{37} / \mathrm{NC}$. Blockage of RhoA/ROCK signaling pathway by Y-27632 selectively inhibits shearstress-stimulated endocytosis of $\mathrm{Ab}_{62} / \mathrm{NC}$. Inhibition of Src family kinases (SFKs) by PP2 specifically blocks flow-stimulated endocytosis of $\mathrm{Ab}_{37} / \mathrm{NC}$.

Understanding the molecular mechanisms and hemodynamic control of Ab/NC internalization is important for rational design of endothelial nanomedicine targeted to specific vascular areas, particularly in those regions where the endothelium is exposed to distinct flow conditions. The context of this paper is limited principally to unidirectional flow typical of small blood vessels and the microcirculation [69], important large reservoirs of endothelial surface area for NC delivery. The ibidi system delivers levels of steady laminar shear stress that are non-pulsatile and are of low Reynolds numbers $(R e)$ - the ratio of inertial forces to viscous forces that quantifies the relative importance of these two types of forces for given flow conditions. In contrast, Re in large arteries are much higher (Re: several hundred to $>2000)$ than in small arterioles and capillaries $($ Re: $<1.0)$ at comparable wall shear stress values. These differences potentially have profound implications for local transport rates at the endothelial surface, an element of obvious importance to NC delivery. Exploration of NC behavior in a high Re model of arterial flow using a large volume, pulsatile fast flow system [70] will investigate complex 
separations of flow (eddies, vortices) typical of athero-susceptible arterial sites [71] and is beyond the scope of the present report.

It would be somewhat naive to attempt to translate our findings into a guidance which type of PECAM-1 ligands (e.g., A $b_{37}$ or $A_{6}$ ) will provide optimal internalization in a vascular area of interest based on the hydrodynamic factors typical of that area. Our knowledge of mechanisms of these processes and ability to determine hydrodynamic characteristics in the patient's vessels (especially those with complex branching and meandering configuration, or/and affected by pathological process) are quite limited. However, our study indicates for the first time that, in theory, such a rational design of epitope-specific intracellular delivery governed by flow is possible. Further, it noteworthy for the drug delivery field that nearly identical carriers binding to the adjacent epitopes on the anchoring molecule may have different targeting features differently modulated by local biological factors including biomechanical conditions. 


\section{CONCLUSION AND PERSPECTIVES.}

CAM-endocytosis offers targeted delivery of NCs into endothelial cells. Our results indicate that flow modulates endothelial endocytosis of $A b / N C$ mediated by PECAM-1 in an epitope-specific manner, via mechanisms involving complex and differential signaling pathways (Fig. 8). The notion that flow modulates endocytosis in a PECAM-1-epitope specific manner and within a certain range of Ab/NC avidities is important in the context of selecting optimal affinity ligands and devising their configuration into drug delivery systems which need to induce intracellular transport while exposed to the circulation. 


\section{METHODS}

Materials. Monoclonal antibodies to human PECAM-1 (anti-PECAM) were Ab62 and $\mathrm{Ab}_{37}$, kindly provided by Dr. Marian Nakada (Centocor) [23]. Fluorescent secondary antibodies were from Invitrogen (Carlsbad, CA). Fluorescein isothiocyanate (FITC) labeled polystyrene spheres (100 nm in diameter) were purchased from Polysciences (Warrington, PA). Methyl- $\beta$-cyclodextrin, Y-27632 and PP2 were obtained from Sigma (St. Louis, MO).

Preparation of anti-PECAM-1/NC. FITC-labeled polystyrene spheres were coated with either anti-PECAM-1 antibodies (A b $_{62}$ or $A_{3} b_{37}$ ) or control murine IgG via incubation at room temperature (RT) for one hour [25]. The reaction mixture was centrifuged to remove unbound materials, then re-suspended in 1\% bovine serum albumin (BSA)-PBS and microsonicated for 20 seconds at low power. The effective immunobead diameter was determined by dynamic light scattering (DLS) using a BI-90 Plus particle size analyzer with BI-9000AT Digital auto-correlator (Brookhaven Instruments, Brookhaven, NY). This protocol yields uniform preparations of anti-PECAM Ab/NC with particle diameters ranging from 180 to $220 \mathrm{~nm}$, indicated thereafter as $A b_{62} / \mathrm{NC}$ and $A b_{37} / \mathrm{NC}$ unless specified otherwise. The saturating antibody surface coverage on the NC surface was estimated to be $\sim 200$ antibody molecules per particle [72]. To prepare Ab/NC with variable antibody surface densities (50 and 200 anti-PECAM molecules per NC), the polystyrene spheres were coated with a mix of anti-PECAM antibody and IgG at molar ratios 1:3, 1:0, respectively, keeping the total amount of IgG molecules coated per particle (including anti-PECAM Ab and $\lg G$ ) constant to avoid variability due to different surface coatings [72].

Cell culture and treatments. endothelial cells used in these studies were human umbilical vein endothelial cells, purchased at passage 1 from Lonza (Walkersville, MD) and cultured for up to six passages in endothelial basal medium (EBM-2) supplemented with EGM-2 Single Quote (Lonza). Cells were starved overnight in EBM-2 containing $0.5 \%$ fetal bovine serum without supplements prior to experiments. Anti-PECAM1 Ab or $\operatorname{lgG}$ coated nanocarriers were then added to HBSS in the reservoir to the final carrier concentration of $2.0 \times 10^{9}$ carriers $/ \mathrm{ml}$ unless specified otherwise, and were perfused for 30 minutes. Thereafter, cells were washed extensively with HBSS to remove unbound particles prior to fixation with $1 \%$ paraformaldehyde for fluorescent staining and analysis.

In the experiments to examine the effects of Methyl- $\beta$-cyclodextrin, Y-27632 and PP2 on endocytosis of $A b_{62} / \mathrm{NC}$ and $A b_{37} / \mathrm{NC}$, endothelial cells were pre-incubated with Methyl- $\beta$-cyclodextrin $(1 \mathrm{mM}), \mathrm{Y}-27632(10 \mu \mathrm{M})$ and PP2 $(10 \mu \mathrm{M})$ for 30 minutes. Thereafter, cells were incubated or perfused with anti-PECAM1 Ab NCs in the presence of Methyl- $\beta$-cyclodextrin, Y-27632 and PP2 for 30 minutes.

The human mesothelioma REN cells stably expressing human wild-type PECAM1 or cytoplasmic domain deleted mutant $\triangle$ PECAM-1 used in this study have been previously described [26]. REN cells were cultured in RPMl1640 medium supplemented with $10 \%$ FBS and Geneticin (G418) as a selection agent.

In vitro laminar shear stress system. A six-channel $\mu$-slide flow chamber (Ibidi, Germany) was used to subject endothelial monolayers to defined laminar shear stress. The chamber was connected to a recirculating flow circuit composed of a variablespeed peristaltic pump (Rainin RP-1, Columbus, $\mathrm{OH}$ ), a reservoir with culture medium, 
and inlet and outlet silicone rubber tubing. The flow rate was calibrated by collecting the volume of medium discharged per minute. The wall shear stress generated by fullydeveloped fluid flow through the channel was calculated using $\tau=6 \mu \mathrm{Q} / \mathrm{h}^{3} \mathrm{w}$, where $\mu$ is the fluid viscosity $\left(\mu=0.70 \mathrm{cP}\right.$ for HBSS at $\left.37^{\circ} \mathrm{C}\right), \mathrm{Q}$ is the mean velocity of the flow through the channel, and $\mathrm{H}$ and $\mathrm{W}$ are the channel height $(0.4 \mathrm{~mm})$ and width $(3.8 \mathrm{~mm})$, respectively. Shear stresses were in the range $0-8 \mathrm{dynes} / \mathrm{cm}^{2}$. The temperature was maintained at $37{ }^{\circ} \mathrm{C}$, and $\mathrm{pH}$ and gases were maintained in a 95\% air/ $5 \% \mathrm{CO}_{2}$ incubation chamber.

Microscopy and quantification of cell-bound and internalized Ab/NC. Endothelial monolayers or REN cells were washed with Hank's balanced salt solution (HBSS) to remove unbound $\mathrm{NC}$ following endothelial uptake of $\mathrm{Ab} / \mathrm{NC}$. Cells were then fixed with $1 \%$ paraformaldehyde for 10 minutes. To distinguish between surface-bound or internalized immunobeads, non-permeabilized fixed cells were counterstained for 30 minutes at RT with Alexa-Fluor-594-conjugated goat anti-mouse IgG to produce doublelabeled, yellow particles. The cells were washed five times with HBSS containing $0.05 \%$ Tween-20, mounted with ProLong Antifade Kit (Molecular probes, Eugene OR) and analyzed by fluorescence microscopy.

Endothelial cells grown in the flow chamber were exposed to flow (4 dyne/ $\left.\mathrm{cm}^{2}\right)$ for 30 minutes. Cells were fixed, permeabilized with $0.1 \%$ Triton X-100 for 15 min, and stained for F-actin (stress fibers) with Alexa-Fluor-594-phalloidin (Molecular probes, Eugene, OR).

Fluorescence microscopy was performed with an Olympus IX70 inverted fluorescence microscope, 40x PlanApo objectives and filters optimized for green fluorescence (excitation BP460-490 nm, dichroic DM570 nm, emission BA515-550 nm) and red fluorescence (excitation BP530-550 nm, dichroic DM570 nm, emission BA590$800+)$. Separate images for each fluorescence channel were acquired using a Hamamatsu Orca-1 CCD camera. The images in green and red channel were merged and analyzed with ImagePro 3.0 imaging software (Media Cybernetics, Silver Spring, MD). Green and red fluorescence images were separately obtained by means of gain and exposure times that were optimized to produce 8-bit images with average background intensity values of approximately 20 bits per pixel and average maximum intensity values of approximately 250 bits per pixel (below saturation). Once the settings were established, they were used for all images obtained for a given sample. For particle quantification, double-labeled particles showing yellow color were identified as surface bound immunobeads by generating a new RBG image merging the green and red channels, and were scored using ImageJ particle analyze plugin with the constraint that only regions with 4 or more continuous pixels and with an intensity threshold of 128 were counted. The green fluorescence image was then scored in a compatible manner to give the total number of immunobeads in the field. Endocytosis was calculated as the percentage of internalized immunobeads with respect to the total number of cellassociated immunobeads. The data are shown as means from $\geq 6$ images \pm S.E. Statistical significance between groups was determined by Student's $t$ test and was accepted as significant at $p<0.05$. 


\section{Acknowledgment.}

This study is supported by R01 HL073940 and HL087036 (V.R.M), U01 EB016027 (D.M.E.), P01 HL062250 and T32 HL007954 (P.F.D.), R01 HL098416 and CBET 1402756 (S.M.), and AHA SDG20140036 (J.H.)

\section{Reference List}

[1] J.A. Champion, S. Mitragotri, Role of target geometry in phagocytosis, Proc. Natl. Acad. Sci. U. S. A. 103 (2006) 4930-4934.

[2] S.E. Gratton, P.A. Ropp, P.D. Pohlhaus, J.C. Luft, V.J. Madden, M.E. Napier, J.M.

DeSimone, The effect of particle design on cellular internalization pathways, Proc. Natl. Acad.

Sci. U. S. A. 105 (2008) 11613-11618.

[3] M.J. Reilly, J.D. Larsen, M.O. Sullivan, Polyplexes Traffic through Caveolae to the Golgi and Endoplasmic Reticulum en Route to the Nucleus, Mol. Pharm. (2012).

[4] D.K. Bonner, C. Leung, J. Chen-Liang, L. Chingozha, R. Langer, P.T. Hammond, Intracellular trafficking of polyamidoamine-poly(ethylene glycol) block copolymers in DNA delivery, Bioconjug. Chem. 22 (2011) 1519-1525.

[5] C.W. Evans, M. Fitzgerald, T.D. Clemons, M.J. House, B.S. Padman, J.A. Shaw, M.

Saunders, A.R. Harvey, B. Zdyrko, I. Luzinov, G.A. Silva, S.A. Dunlop, K.S. Iyer, Multimodal analysis of PEI-mediated endocytosis of nanoparticles in neural cells, ACS Nano. 5 (2011) 86408648.

[6] B.D. Holt, K.N. Dahl, M.F. Islam, Cells Take up and Recover from Protein-Stabilized Single-Wall Carbon Nanotubes with Two Distinct Rates, ACS Nano. 6 (2012) 3481-3490. [7] E. Oh, J.B. Delehanty, K.E. Sapsford, K. Susumu, R. Goswami, J.B. Blanco-Canosa, P.E. Dawson, J. Granek, M. Shoff, Q. Zhang, P.L. Goering, A. Huston, I.L. Medintz, Cellular uptake and fate of PEGylated gold nanoparticles is dependent on both cell-penetration peptides and particle size, ACS Nano. 5 (2011) 6434-6448.

[8] T. Skotland, T.G. Iversen, K. Sandvig, Comment on "short ligands affect modes of QD uptake and elimination in human cells", ACS Nano. 5 (2011) 7690; author reply 7691-2. [9] P.F. Davies, Flow-mediated endothelial mechanotransduction, Physiol. Rev. 75 (1995) 519560.

[10] P. Charoenphol, R.B. Huang, O. Eniola-Adefeso, Potential role of size and hemodynamics in the efficacy of vascular-targeted spherical drug carriers, Biomaterials. 31 (2010) 1392-1402. [11] A.J. Calderon, V. Muzykantov, S. Muro, D.M. Eckmann, Flow dynamics, binding and detachment of spherical carriers targeted to ICAM-1 on endothelial cells, Biorheology. 46 (2009) 323-341.

[12] T. Bhowmick, E. Berk, X. Cui, V.R. Muzykantov, S. Muro, Effect of flow on endothelial endocytosis of nanocarriers targeted to ICAM-1, J. Control. Release. (2011). [13] A. Lin, A. Sabnis, S. Kona, S. Nattama, H. Patel, J.F. Dong, K.T. Nguyen, Shear-regulated uptake of nanoparticles by endothelial cells and development of endothelial-targeting nanoparticles, J. Biomed. Mater. Res. A. 93 (2010) 833-842. 
[14] R. Igarashi, M. Takenaga, J. Takeuchi, A. Kitagawa, K. Matsumoto, Y. Mizushima, Marked hypotensive and blood flow-increasing effects of a new lipo-PGE(1) (lipo-AS013) due to vascular wall targeting, J. Control. Release. 71 (2001) 157-164.

[15] P. Charoenphol, P.J. Onyskiw, M. Carrasco-Teja, O. Eniola-Adefeso, Particle-cell dynamics in human blood flow: implications for vascular-targeted drug delivery, J. Biomech. 45 (2012) 2822-2828.

[16] S.P. Samuel, N. Jain, F. O'Dowd, T. Paul, D. Kashanin, V.A. Gerard, Y.K. Gun'ko, A. Prina-Mello, Y. Volkov, Multifactorial determinants that govern nanoparticle uptake by human endothelial cells under flow, Int. J. Nanomedicine. 7 (2012) 2943-2956.

[17] K.T. Nguyen, K.P. Shukla, M. Moctezuma, A.R. Braden, J. Zhou, Z. Hu, L. Tang, Studies of the cellular uptake of hydrogel nanospheres and microspheres by phagocytes, vascular endothelial cells, and smooth muscle cells, J. Biomed. Mater. Res. A. 88 (2009) 1022-1030. [18] J. Han, B.J. Zern, V.V. Shuvaev, P.F. Davies, S. Muro, V. Muzykantov, Acute and chronic shear stress differently regulate endothelial internalization of nanocarriers targeted to plateletendothelial cell adhesion molecule-1, ACS Nano. 6 (2012) 8824-8836.

[19] M. Chorny, E. Hood, R.J. Levy, V.R. Muzykantov, Endothelial delivery of antioxidant enzymes loaded into non-polymeric magnetic nanoparticles, J. Control. Release. 146 (2010) 144151.

[20] B.S. Ding, N. Hong, M. Christofidou-Solomidou, C. Gottstein, S.M. Albelda, D.B. Cines, A.B. Fisher, V.R. Muzykantov, Anchoring fusion thrombomodulin to the endothelial lumen protects against injury-induced lung thrombosis and inflammation, Am. J. Respir. Crit. Care Med. 180 (2009) 247-256.

[21] V.V. Shuvaev, J. Han, K.J. Yu, S. Huang, B.J. Hawkins, M. Madesh, M. Nakada, V.R. Muzykantov, PECAM-targeted delivery of SOD inhibits endothelial inflammatory response, FASEB J. 25 (2011) 348-357.

[22] J. Han, V.V. Shuvaev, V.R. Muzykantov, Catalase and superoxide dismutase conjugated with platelet-endothelial cell adhesion molecule antibody distinctly alleviate abnormal endothelial permeability caused by exogenous reactive oxygen species and vascular endothelial growth factor, J. Pharmacol. Exp. Ther. 338 (2011) 82-91.

[23] V.R. Muzykantov, M. Christofidou-Solomidou, I. Balyasnikova, D.W. Harshaw, L. Schultz, A.B. Fisher, S.M. Albelda, Streptavidin facilitates internalization and pulmonary targeting of an anti-endothelial cell antibody (platelet-endothelial cell adhesion molecule 1): a strategy for vascular immunotargeting of drugs, Proc. Natl. Acad. Sci. U. S. A. 96 (1999) 2379-2384. [24] R. Wiewrodt, A.P. Thomas, L. Cipelletti, M. Christofidou-Solomidou, D.A. Weitz, S.I. Feinstein, D. Schaffer, S.M. Albelda, M. Koval, V.R. Muzykantov, Size-dependent intracellular immunotargeting of therapeutic cargoes into endothelial cells, Blood. 99 (2002) 912-922. [25] S. Muro, R. Wiewrodt, A. Thomas, L. Koniaris, S.M. Albelda, V.R. Muzykantov, M. Koval, A novel endocytic pathway induced by clustering endothelial ICAM-1 or PECAM-1, J. Cell. Sci. 116 (2003) 1599-1609.

[26] C. Garnacho, V. Shuvaev, A. Thomas, L. McKenna, J. Sun, M. Koval, S. Albelda, V. Muzykantov, S. Muro, RhoA activation and actin reorganization involved in endothelial CAMmediated endocytosis of anti-PECAM carriers: critical role for tyrosine 686 in the cytoplasmic tail of PECAM-1, Blood. 111 (2008) 3024-3033.

[27] J. Liu, G.E. Weller, B. Zern, P.S. Ayyaswamy, D.M. Eckmann, V.R. Muzykantov, R. Radhakrishnan, Computational model for nanocarrier binding to endothelium validated using in 
vivo, in vitro, and atomic force microscopy experiments, Proc. Natl. Acad. Sci. U. S. A. 107 (2010) 16530-16535.

[28] N. Ilan, J.A. Madri, PECAM-1: old friend, new partners, Curr. Opin. Cell Biol. 15 (2003) 515-524.

[29] A. Woodfin, M.B. Voisin, S. Nourshargh, PECAM-1: a multi-functional molecule in inflammation and vascular biology, Arterioscler. Thromb. Vasc. Biol. 27 (2007) 2514-2523.

[30] J.R. Privratsky, D.K. Newman, P.J. Newman, PECAM-1: conflicts of interest in inflammation, Life Sci. 87 (2010) 69-82.

[31] V.R. Muzykantov, Delivery of antioxidant enzyme proteins to the lung, Antioxid. Redox Signal. 3 (2001) 39-62.

[32] A. Scherpereel, J.J. Rome, R. Wiewrodt, S.C. Watkins, D.W. Harshaw, S. Alder, M. Christofidou-Solomidou, E. Haut, J.C. Murciano, M. Nakada, S.M. Albelda, V.R. Muzykantov, Platelet-endothelial cell adhesion molecule-1-directed immunotargeting to cardiopulmonary vasculature, J. Pharmacol. Exp. Ther. 300 (2002) 777-786.

[33] B.S. Ding, N. Hong, J.C. Murciano, K. Ganguly, C. Gottstein, M. Christofidou-Solomidou, S.M. Albelda, A.B. Fisher, D.B. Cines, V.R. Muzykantov, Prophylactic thrombolysis by thrombin-activated latent prourokinase targeted to PECAM-1 in the pulmonary vasculature, Blood. 111 (2008) 1999-2006.

[34] T.D. Dziubla, V.V. Shuvaev, N.K. Hong, B.J. Hawkins, M. Madesh, H. Takano, E. Simone, M.T. Nakada, A. Fisher, S.M. Albelda, V.R. Muzykantov, Endothelial targeting of semipermeable polymer nanocarriers for enzyme therapies, Biomaterials. 29 (2008) 215-227. [35] J. Hsu, L. Northrup, T. Bhowmick, S. Muro, Enhanced delivery of alpha-glucosidase for Pompe disease by ICAM-1-targeted nanocarriers: comparative performance of a strategy for three distinct lysosomal storage disorders, Nanomedicine. (2011).

[36] S. Muro, New biotechnological and nanomedicine strategies for treatment of lysosomal storage disorders, Wiley Interdiscip. Rev. Nanomed Nanobiotechnol. 2 (2010) 189-204. [37] M.T. Nakada, K. Amin, M. Christofidou-Solomidou, C.D. O'Brien, J. Sun, I. Gurubhagavatula, G.A. Heavner, A.H. Taylor, C. Paddock, Q.H. Sun, J.L. Zehnder, P.J. Newman, S.M. Albelda, H.M. DeLisser, Antibodies against the first Ig-like domain of human platelet endothelial cell adhesion molecule-1 (PECAM-1) that inhibit PECAM-1-dependent homophilic adhesion block in vivo neutrophil recruitment, J. Immunol. 164 (2000) 452-462. [38] A.M. Chacko, M. Nayak, C.F. Greineder, H.M. Delisser, V.R. Muzykantov, Collaborative enhancement of antibody binding to distinct PECAM-1 epitopes modulates endothelial targeting, PLoS One. 7 (2012) e34958.

[39] P.S. Ayyaswamy, V. Muzykantov, D.M. Eckmann, R. Radhakrishnan, Nanocarrier Hydrodynamics and Binding in Targeted Drug Delivery: Challenges in Numerical Modeling and Experimental Validation, J. Nanotechnol Eng. Med. 4 (2013) 101011-1010115.

[40] P.F. Davies, C.F. Dewey Jr, S.R. Bussolari, E.J. Gordon, M.A. Gimbrone Jr, Influence of hemodynamic forces on vascular endothelial function. In vitro studies of shear stress and pinocytosis in bovine aortic cells, J. Clin. Invest. 73 (1984) 1121-1129.

[41] E.A. Sprague, B.L. Steinbach, R.M. Nerem, C.J. Schwartz, Influence of a laminar steadystate fluid-imposed wall shear stress on the binding, internalization, and degradation of lowdensity lipoproteins by cultured arterial endothelium, Circulation. 76 (1987) 648-656.

[42] V. Raghavan, Y. Rbaibi, N.M. Pastor-Soler, M.D. Carattino, O.A. Weisz, Shear stressdependent regulation of apical endocytosis in renal proximal tubule cells mediated by primary cilia, Proc. Natl. Acad. Sci. U. S. A. 111 (2014) 8506-8511. 
[43] C. Collins, E. Tzima, RhoA goes GLOBAL, Small GTPases. 4 (2013) 123-126.

[44] C. Garnacho, R. Dhami, E. Simone, T. Dziubla, J. Leferovich, E.H. Schuchman, V. Muzykantov, S. Muro, Delivery of acid sphingomyelinase in normal and niemann-pick disease mice using intercellular adhesion molecule-1-targeted polymer nanocarriers, J. Pharmacol. Exp. Ther. 325 (2008) 400-408.

[45] R.J. Marjoram, E.C. Lessey, K. Burridge, Regulation of RhoA activity by adhesion molecules and mechanotransduction, Curr. Mol. Med. 14 (2014) 199-208.

[46] D. Serrano, T. Bhowmick, R. Chadha, C. Garnacho, S. Muro, Intercellular adhesion molecule 1 engagement modulates sphingomyelinase and ceramide, supporting uptake of drug carriers by the vascular endothelium, Arterioscler. Thromb. Vasc. Biol. 32 (2012) 1178-1185. [47] S. Muro, M. Mateescu, C. Gajewski, M. Robinson, V.R. Muzykantov, M. Koval, Control of intracellular trafficking of ICAM-1-targeted nanocarriers by endothelial $\mathrm{Na}+\mathrm{H}+$ exchanger proteins, Am. J. Physiol. Lung Cell. Mol. Physiol. 290 (2006) L809-17.

[48] C. Collins, C. Guilluy, C. Welch, E.T. O'Brien, K. Hahn, R. Superfine, K. Burridge, E. Tzima, Localized tensional forces on PECAM-1 elicit a global mechanotransduction response via the integrin-RhoA pathway, Curr. Biol. 22 (2012) 2087-2094.

[49] K. Fujiwara, Platelet endothelial cell adhesion molecule-1 and mechanotransduction in vascular endothelial cells, J. Intern. Med. 259 (2006) 373-380.

[50] D.A. Kaufman, S.M. Albelda, J. Sun, P.F. Davies, Role of lateral cell-cell border location and extracellular/transmembrane domains in PECAM/CD31 mechanosensation, Biochem. Biophys. Res. Commun. 320 (2004) 1076-1081.

[51] M. Masuda, N. Kogata, N. Mochizuki, Crucial roles of PECAM-1 in shear stress sensing of vascular endothelial cells, Nippon Yakurigaku Zasshi. 124 (2004) 311-318.

[52] P.J. Newman, D.K. Newman, Signal transduction pathways mediated by PECAM-1: new roles for an old molecule in platelet and vascular cell biology, Arterioscler. Thromb. Vasc. Biol. 23 (2003) 953-964.

[53] C. Garnacho, S.M. Albelda, V.R. Muzykantov, S. Muro, Differential intra-endothelial delivery of polymer nanocarriers targeted to distinct PECAM-1 epitopes, J. Control. Release. 130 (2008) 226-233.

[54] S.M. Thomas, J.S. Brugge, Cellular functions regulated by Src family kinases, Annu. Rev. Cell Dev. Biol. 13 (1997) 513-609.

[55] T.J. Yeatman, A renaissance for SRC, Nat. Rev. Cancer. 4 (2004) 470-480.

[56] Y.J. Chiu, E. McBeath, K. Fujiwara, Mechanotransduction in an extracted cell model: Fyn drives stretch- and flow-elicited PECAM-1 phosphorylation, J. Cell Biol. 182 (2008) 753-763.

[57] T.T. Lu, M. Barreuther, S. Davis, J.A. Madri, Platelet endothelial cell adhesion molecule-1 is phosphorylatable by c-Src, binds Src-Src homology 2 domain, and exhibits immunoreceptor tyrosine-based activation motif-like properties, J. Biol. Chem. 272 (1997) 14442-14446.

[58] D.E. Jackson, K.R. Kupcho, P.J. Newman, Characterization of phosphotyrosine binding motifs in the cytoplasmic domain of platelet/endothelial cell adhesion molecule-1 (PECAM-1) that are required for the cellular association and activation of the protein-tyrosine phosphatase, SHP-2, J. Biol. Chem. 272 (1997) 24868-24875.

[59] M.Y. Cao, M. Huber, N. Beauchemin, J. Famiglietti, S.M. Albelda, A. Veillette, Regulation of mouse PECAM-1 tyrosine phosphorylation by the Src and Csk families of protein-tyrosine kinases, J. Biol. Chem. 273 (1998) 15765-15772. 
[60] A.N. Shajahan, B.K. Timblin, R. Sandoval, C. Tiruppathi, A.B. Malik, R.D. Minshall, Role of Src-induced dynamin-2 phosphorylation in caveolae-mediated endocytosis in endothelial cells, J. Biol. Chem. 279 (2004) 20392-20400.

[61] A. Zloza, D.W. Kim, J. Broucek, J.M. Schenkel, H.L. Kaufman, High-dose IL-2 induces rapid albumin uptake by endothelial cells through Src-dependent caveolae-mediated endocytosis, J. Interferon Cytokine Res. 34 (2014) 915-919.

[62] Y. Xing, Y. Gu, L.C. Xu, C.A. Siedlecki, H.J. Donahue, J. You, Effects of membrane cholesterol depletion and GPI-anchored protein reduction on osteoblastic mechanotransduction, J. Cell. Physiol. 226 (2011) 2350-2359.

[63] P. Lajoie, I.R. Nabi, Lipid rafts, caveolae, and their endocytosis, Int. Rev. Cell. Mol. Biol. 282 (2010) 135-163.

[64] J.T. Ferraro, M. Daneshmand, R. Bizios, V. Rizzo, Depletion of plasma membrane cholesterol dampens hydrostatic pressure and shear stress-induced mechanotransduction pathways in osteoblast cultures, Am. J. Physiol. Cell. Physiol. 286 (2004) C831-9.

[65] I.R. Nabi, P.U. Le, Caveolae/raft-dependent endocytosis, J. Cell Biol. 161 (2003) 673-677. [66] R.C. Laughlin, G.C. McGugan, R.R. Powell, B.H. Welter, L.A. Temesvari, Involvement of raft-like plasma membrane domains of Entamoeba histolytica in pinocytosis and adhesion, Infect. Immun. 72 (2004) 5349-5357.

[67] S. Grimmer, B. van Deurs, K. Sandvig, Membrane ruffling and macropinocytosis in A431 cells require cholesterol, J. Cell. Sci. 115 (2002) 2953-2962.

[68] S. Muro, X. Cui, C. Gajewski, J.C. Murciano, V.R. Muzykantov, M. Koval, Slow intracellular trafficking of catalase nanoparticles targeted to ICAM-1 protects endothelial cells from oxidative stress, Am. J. Physiol. Cell. Physiol. 285 (2003) C1339-47.

[69] A.G. Koutsiaris, S.V. Tachmitzi, N. Batis, M.G. Kotoula, C.H. Karabatsas, E. Tsironi, D.Z. Chatzoulis, Volume flow and wall shear stress quantification in the human conjunctival capillaries and post-capillary venules in vivo, Biorheology. 44 (2007) 375-386. [70] J.M. Jimenez, V. Prasad, M.D. Yu, C.P. Kampmeyer, A.H. Kaakour, P.J. Wang, S.F. Maloney, N. Wright, I. Johnston, Y.Z. Jiang, P.F. Davies, Macro- and microscale variables regulate stent haemodynamics, fibrin deposition and thrombomodulin expression, J. R. Soc. Interface. 11 (2014) 20131079.

[71] P.F. Davies, Hemodynamic shear stress and the endothelium in cardiovascular pathophysiology, Nat. Clin. Pract. Cardiovasc. Med. 6 (2009) 16-26.

[72] S. Muro, T. Dziubla, W. Qiu, J. Leferovich, X. Cui, E. Berk, V.R. Muzykantov, Endothelial targeting of high-affinity multivalent polymer nanocarriers directed to intercellular adhesion molecule 1, J. Pharmacol. Exp. Ther. 317 (2006) 1161-1169. 


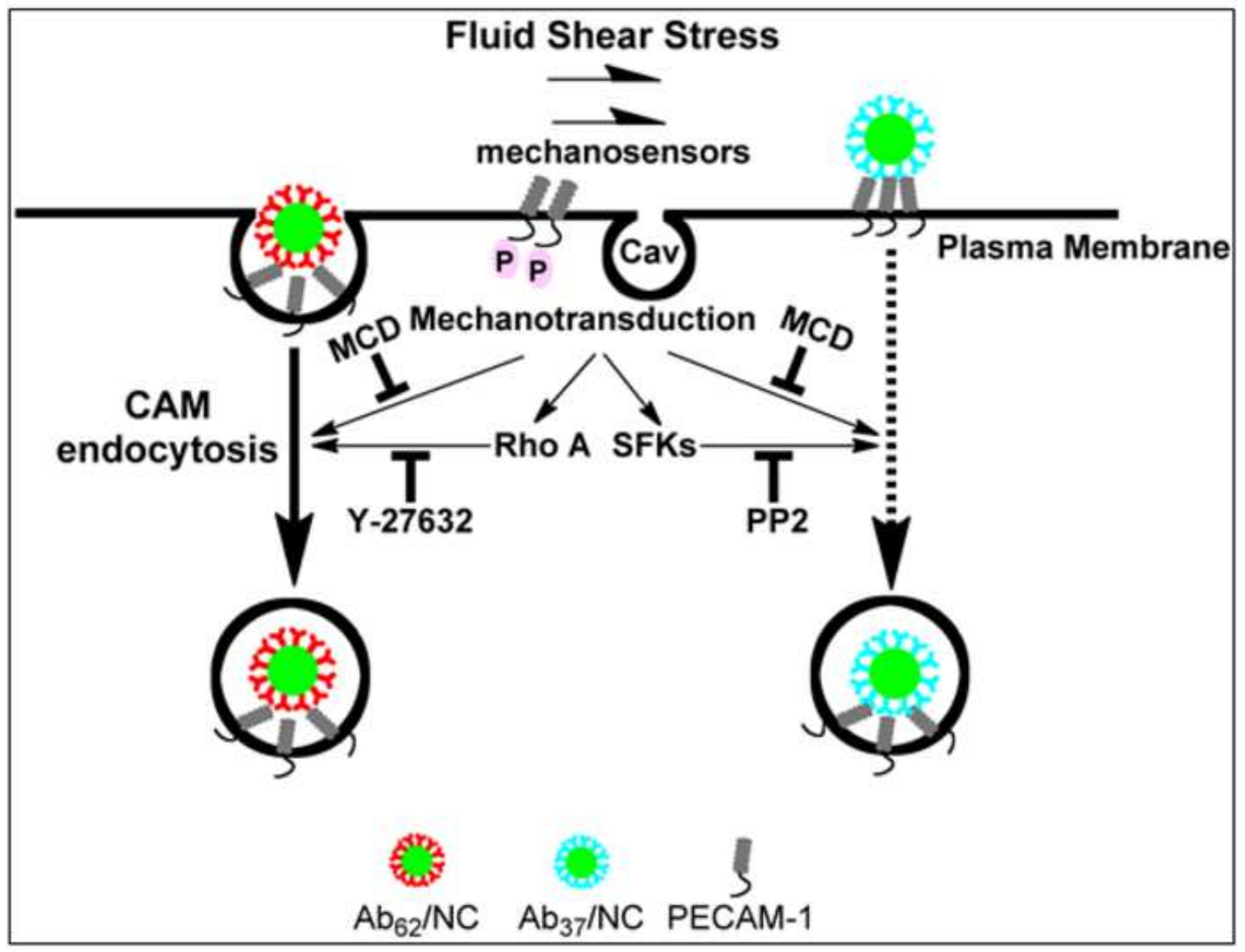

